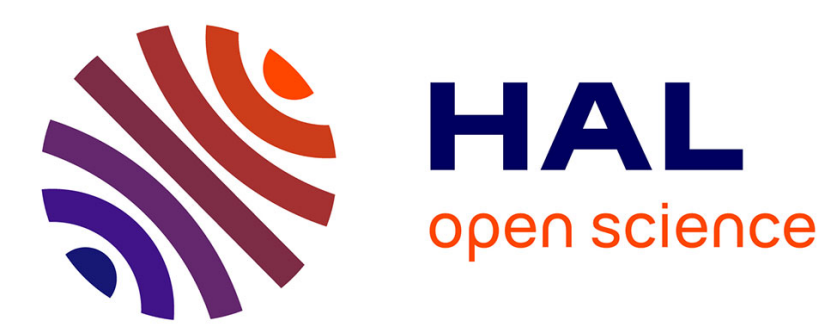

\title{
Using multiscale spatial analysis to assess fire ignition density in Catalonia, Spain
}

Jose Gonzalez-Olabarria, Mola-Yudego, Pukkala, Palahi

\section{To cite this version:}

Jose Gonzalez-Olabarria, Mola-Yudego, Pukkala, Palahi. Using multiscale spatial analysis to assess fire ignition density in Catalonia, Spain. Annals of Forest Science, 2011, 68 (4), pp.861-871. 10.1007/s13595-011-0082-2 . hal-00930815

\section{HAL Id: hal-00930815 https://hal.science/hal-00930815}

Submitted on 1 Jan 2011

HAL is a multi-disciplinary open access archive for the deposit and dissemination of scientific research documents, whether they are published or not. The documents may come from teaching and research institutions in France or abroad, or from public or private research centers.
L'archive ouverte pluridisciplinaire HAL, est destinée au dépôt et à la diffusion de documents scientifiques de niveau recherche, publiés ou non, émanant des établissements d'enseignement et de recherche français ou étrangers, des laboratoires publics ou privés. 


\title{
Using multiscale spatial analysis to assess fire ignition density in Catalonia, Spain
}

\author{
Jose Ramon Gonzalez-Olabarria • Blas Mola-Yudego • \\ Timo Pukkala $•$ Marc Palahi
}

Received: 4 June 2010 /Accepted: 4 January 2011 /Published online: 31 May 2011

(C) INRA and Springer Science+Business Media B.V. 2011

\begin{abstract}
- Introduction This article explores the possibility of including multiple spatial scales into a mixed model for predicting the density of human-caused fire ignitions in Catalonia (North-East Spain).

- Methods The location of the ignitions of all humancaused forest fires recorded in Catalonia during the period 1994-2007, including 7,847 human-caused fires, was considered as modeling data. Three spatial scales were considered in the modeling. The first or small spatial scale was defined by tiling 3,003 hexagonal plots of 1,000 ha each. The two remaining spatial scales were defined by the inclusion of the plots within municipality and county (comarca) borders. Fire ignition density was estimated at plot level using proxy variables as predictors (elevation, presence of roads, density of pathways, and dominant land-use patterns). The administrative borders of municipality and county were used to allocate the spatial variation of ignition density not explained by the plot-level estimation.
\end{abstract}

\section{Handling Editor: Michael Tausz}

J. R. Gonzalez-Olabarria $(\triangle)$

Centre Tecnològic Forestal de Catalunya (CTFC),

Ctra St. Llorenc de Munys, Km 2,

25280 Solsona, Spain

e-mail: jr.gonzalez@ctfc.es

\section{Palahi}

Mediterranean Regional Office of the

European Forest Institute (EFIMED),

Castella 33-Esc. 2 - $3^{\circ}$-pta 2 ,

08018 Barcelona, Spain

B. Mola-Yudego $\cdot$ T. Pukkala

School of Forest Sciences, University of Eastern Finland,

P.O. Box 111, 80101 Joensuu, Finland
- Conclusions The results of the study highlight that human-caused ignitions present clear spatial aggregation patterns at different spatial scales, and that an analysis at a single spatial scale ignores explanatory factors affecting other scales.

Keywords Fire ignitions · Mixed effects models · Spatial aggregation $\cdot$ Risk mapping

\section{Introduction}

Analysis of the fire regime in Catalonia does not suggest easy times ahead for the people in charge of fire prevention and suppression. Although the area affected by wildfires has not changed significantly during the last 30 years, research reports that there has been a significant increment in the number of large fires (Gonzalez and Pukkala 2007). Many factors have been mentioned as possible causes for this change in fire regime, including changes in landscape configuration and forest management (Badia et al. 2002; Velez 2002), climate change (Piñol et al. 1998), and the increasing prevalence of human-related ignitions (Vazquez and Moreno 1995). In highly populated regions such as Catalonia, analysis of human-caused fires is especially relevant since natural-caused fires account for less than $20 \%$ of the total number of forest fire outbreaks (DGMN 2005).

There is broad consensus on the need for a clear understanding of the factors affecting the occurrence of fire ignitions and spread of forest fires in order to develop more effective fire suppression and extinction policies (Badia-Perpinya and Pallares-Barbera 2006). Analysis of historical records of fire ignitions can contribute to an 
understanding of which local-landscape features facilitate the ignition and spread of forest fires. In addition, models developed to predict the location of areas where ignitions are more likely to occur have a crucial role to play in optimizing fire prevention strategies.

However, the study of the human component as a cause of fires carries an implicit difficulty in itself (Martinez et al. 2004). Human behavior is dynamic and varies for each individual, and regional- or national-scale information on specific human activities is seldom available. For this reason, most of the studies dealing with the effect of human activities on the probability of occurrence or frequency of fire ignitions in a certain area rely mainly on cartographic data of human infrastructures (e.g., roads, houses, electricity lines, railroads, campsites) or general socioeconomic indicators characterizing the area (e.g., population density, presence of farmland, rent distribution, unemployment levels).

Different approaches have been considered to solve the difficulties of modeling human-caused fire ignitions with a spatially explicit approach. Some studies have attempted to predict the probability of fire occurrence using logistic models (Martell et al. 1987; Chou et al. 1993; Vega Garcia et al. 1995; Cardille et al. 2001; Vasconcelos et al. 2001; Pew and Larsen 2001; Martinez et al. 2004; Catry et al. 2009; Martinez et al. 2008), artificial neural networks (Vasconcellos et al. 2001; Vega Garcia et al. 1999), or weights of evidence (Romero-Calcerrada et al. 2008), while others have focused on modeling the frequency or density of fires in a determined area using generalized linear regression (Cardille et al. 2001), Poisson regression (Wotton et al. 2003), fuzzy logic (Loboda and Czizar 2007), multiple linear regression (Syphard et al. 2007), or log-linear regression (Yang et al. 2007).

In general, most of these studies have been performed using a single spatial scale (Cardille et al. 2001). In some cases, a fine-scale spatial analysis is used to assess the influence of local factors on fire occurrence or frequency. Fine-scale studies can be based on the location of a regular grid of cells with information on ignition events within their boundaries (Cardille et al. 2001; Pew and Larsen 2001; Yang et al. 2007), based solely on the specific location of the ignitions (RomeroCalcerrada et al. 2008), or on the location of ignitions versus the location of a random number of points considered as non-ignition representatives (Martell et al. 1987; Vega Garcia et al. 1995; Vasconcelos et al. 2001; Catry et al. 2009). In other cases, a broad scale has been used to analyze the effect of aggregated factors on the frequency or occurrence of fires. Broad-scale studies have been implemented at municipality level (De la Riva et al. 2004; Martinez et al. 2008), county level (Prestemon et al. 2002; Badia-Perpinya and Pallares-Barbera 2006; Syphard et al. 2007), or ecological region level (Chou et al. 1993; Wotton et al. 2003).

Human-caused fire ignitions do however tend to be spatially aggregated at different levels simultaneously. Aggregation is rarely distributed uniformly across the territory (Prestemon and Butry 2005; Genton et al. 2006), and the use of a single spatial scale does not fully address relevant local variation (Martinez et al. 2004). In addition, there may be confounding effects of variables working in different ways at different levels, which complicates the analysis. The use of different spatial scales could usefully address the effect of overall features of the territory (fine scale) while at the same time capturing spatial variations within the territory (broad scale). One way to address this data structure is to use multilevel models such as the mixed linear model. The mixed model can analyze data aggregated hierarchically, as it estimates variability due to the different levels of aggregation. By this means, it helps to understand how ignition distribution is shaped by effects such as localized land use configurations at a localized scale as well as the effects of socioeconomic variables at a broader scale, and subsequently estimate the weights of these levels to avoid possible confounding effects. Furthermore, using estimates at every hierarchical level incorporates the spatial variability of the studied factors at the levels considered, which can for example be used to identify municipalities and regions with specific characteristics that result in a higher exposure to forest ignitions. An example of this approach can be found in Diaz-Avalos et al. (2001), who successfully applied a generalized linear mixed model to study the probability of lightning-caused ignitions using different spatial and temporal scales.

The aim of the present study was to develop a multiscale analysis-based model to map the density of human-caused fire ignitions in the Catalonia region. The model is designed to provide information on the impact of local variables on ignition density, as well as to describe the spatial variation observed across the territory, highlighting those areas that may require special attention.

\section{Material and methods}

\subsection{Data sources}

The study area encloses the whole region of Catalonia (North-East Spain), which covers an area of over $32,000 \mathrm{~km}^{2}$ and has a population of around 7.5 million inhabitants.

The data used in the model consisted of geographically referenced records of forest fire ignitions, orographic data, land-cover maps, and human-made infrastructures. Maps of 
Fig. 1 Representation of study plots and selection variables studied. Black triangles represent historic fire ignitions, thick gray lines represent paved roads, and narrow black lines represent smaller pathways

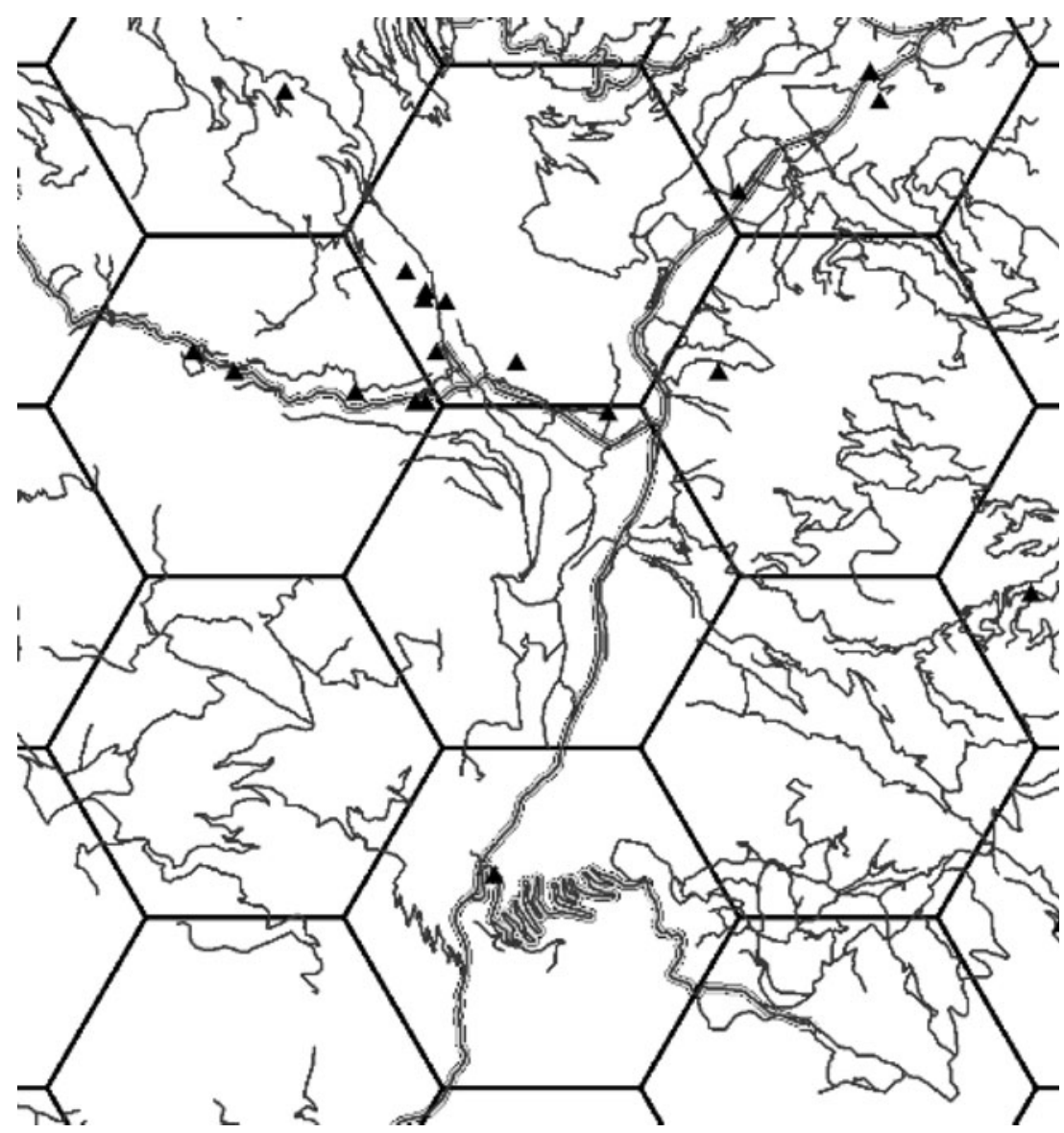

the administrative divisions were used to define different levels of spatial aggregation.

The fire ignition-related data consists of the ignition location of human-caused fires recorded in Catalonia during the period 1994-2007. The dataset covered a total of 10,320 fires larger than 0.01 ha, of which 7,847 were human-caused. Orography data were obtained from a digital terrain model of Catalonia (resolution $150 \mathrm{~m}$ ). Data on human infrastructures were obtained from the Catalonian topographic database (scale 1:50,000), while land-cover information was derived from the Spanish forest map at scale 1:50,000 (MFE50; BDN 2001).
In order to analyze the effects of different levels of spatial aggregation on ignition density, administrative boundaries were used as aggregation units. Two different levels of aggregation were used: municipal level and comarca (county) level. Catalonia consists of 41 comarcas, or counties, with an average area of $783.07 \mathrm{~km}^{2}$ (ranging from 144 to $1,783 \mathrm{~km}^{2}$ ), which are further divided into approximately 900 municipalities with an average area of $30.81 \mathrm{~km}^{2}$ (ranging from 0.5 to $255 \mathrm{~km}^{2}$ ).

The effects of different factors on ignitions density were analyzed in the following steps. First, a hexagonal tiling formed by 3,003 hexagonal 1,000-ha plots was generated
Table 1 Summary of the plotlevel variables included in the models

\begin{tabular}{llllll}
\hline Variable & Unit & Mean & Minimum & Maximum & Standard deviation \\
\hline Plot-level variables & & & & & \\
Elevation & Meters (a.s.l.) & 802 & 0 & 2,800 & 589 \\
Density of pathways & $\mathrm{km} / \mathrm{km}^{2}$ & 4.772 & 0 & 19.4 & 2.114 \\
Paved road presence & - & 0.712 & 0 & 1 & 0.453 \\
Urban & - & 0.003 & 0 & 1 & 0.057 \\
Agriculture-forest interface & - & 0.359 & 0 & 1 & 0.480 \\
Urban-rural interface & - & 0.050 & 0 & 1 & 0.217 \\
Ignition density (human) & Ignitions $/ \mathrm{km}^{2}$ & 0.235 & 0 & 7.90 & 0.423 \\
\hline
\end{tabular}


within the borders of the study region (Fig. 1). Each plot was used as a study unit, and ignitions density (ignitions per square kilometer) was calculated for each plot and used as the predicted variable in subsequent modeling. The criteria used to define the size of the hexagons were based on the observed average distance between ignitions in our study dataset $(2,500.6 \mathrm{~m}$ during 1994-2007 for human-caused ignitions), this magnitude being larger than the distance of the hexagon apothem and smaller than the distance between the centers of adjacent hexagons. The use of hexagons was justified by the need to avoid overlapping areas that may lead to ignition doublecounts while at the same time optimizing the isotropic nature of the sampling method. Values of potential predictors were estimated for each plot. Potential predictors were selected based on two different criteria. They had to be variables known to affect ignitions regime, while at the same time being representative of the plot area. Based on these approaches, variables such as pathway density, mean elevation, and presence or absence of paved roads belonging to the national road network inside the plot were considered as predictors (Table 1).

Second, the plots were classified depending on their share of different land-use patterns. A threshold of more than $80 \%$ of the plot surface was considered as a criterion to classify the plot as either forest, urban, or agricultural land. Plots sharing more than $20 \%$ of two different land-uses, one of which was urban land, were classified as urban-rural interface. Plots sharing forest and agricultural land-uses (more than $20 \%$ of forest and more than $20 \%$ of agricultural land but less than $20 \%$ of urban land) were defined as agriculture-forest interface.

Third, the plot-level variables were calculated, and the plots were grouped following two levels of aggregation: municipal level and county level (Fig. 2).

\subsection{Ignition model}

A model was developed to predict the density of fire ignitions per kilometer. In general, we assumed that the density of fire ignitions in a given plot correlates to a set of proxy variables that determine the conditions of the area. The predictors used in the model had to be significant at the 0.05 level, non-linearly correlated, and with residuals that indicate a non-biased model. However, a regression model assumes that the responses of every single plot are independent. Although this assumption can hold in some cases, the spatial nature of the data suggest that neighboring plots may be influenced by the same factors at different levels (for instance, socioeconomic factors that determine similar

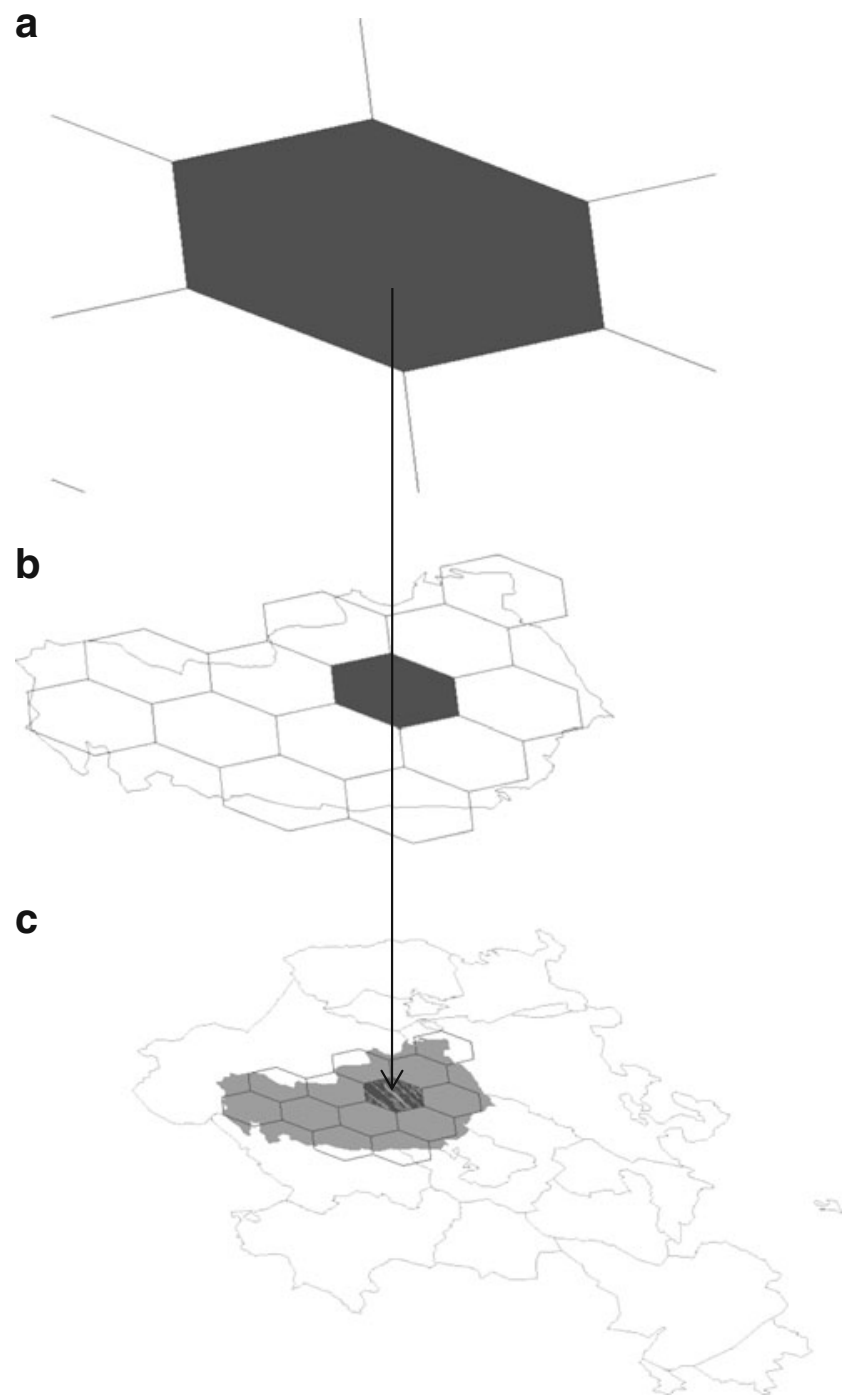

Fig. 2 Multilevel data structure for the modeling approach. Ignitions were aggregated by hexagonal plots (a). The plots were then aggregated following municipal (b) or county (c) boundaries

conditions in an area, macroclimatic factors that determine vegetation covers, etc.). Following the current administrative division system, plots can belong to the same municipality, and municipalities can belong to the same county. Given the hierarchical structure of the data and the grouping of study plots by municipalities and counties, we elected to use a mixed linear model approach including fixed and random components. This option enabled us to address the potential problem of autocorrelation in the data due to geographical proximity between plots, as well as separating effects that act at different spatial scales. The model was fitted using the restricted maximum likelihood (REML) procedure in $\mathrm{R}$ to avoid potential problems of biased estimators with 
Fig. 3 Measured versus predicted values of human-caused ignition density (ignitions per square kilometer) for the fixed part of the model (a), for the mixed model including both county and municipality effect (b), and the mixed model including the effect of the each of the random effects separately (county c; municipality d)

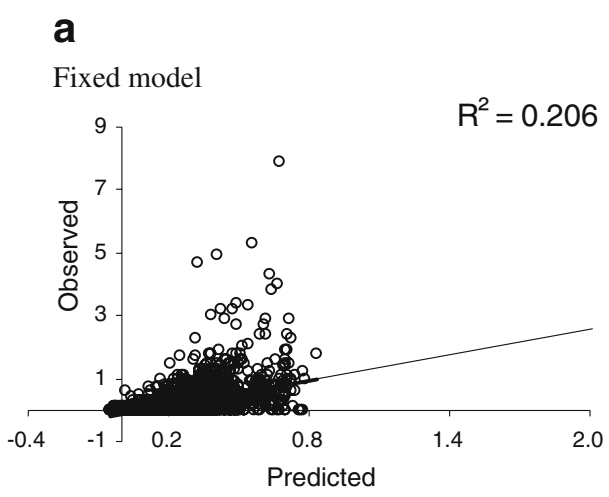

C

Mixed model (County effect)

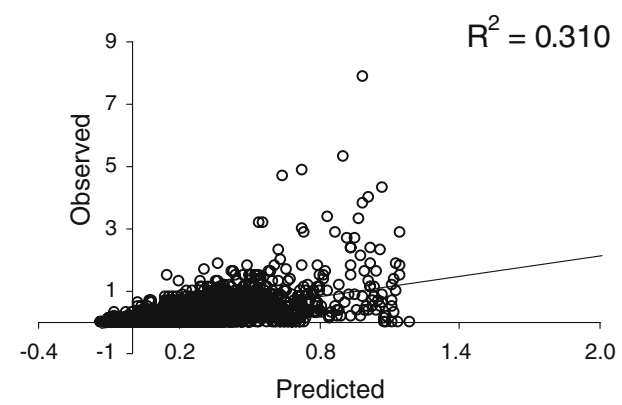

b

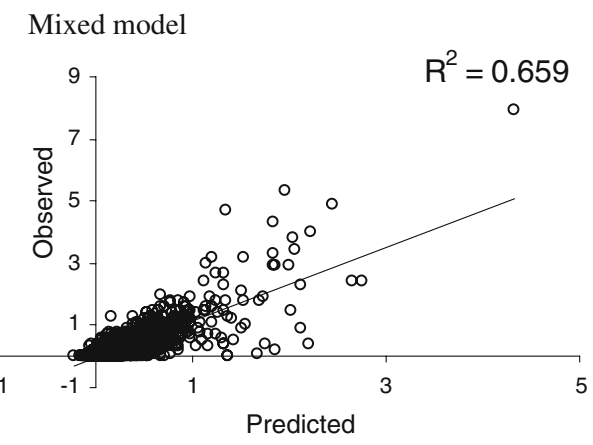

d

Mixed model (Municipality effect)

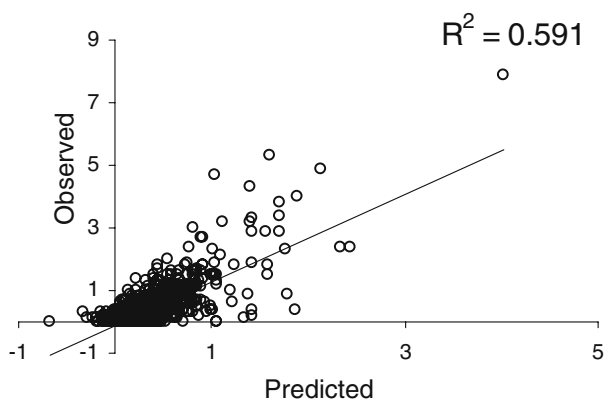

unbalanced data (Pinheiro and Bates 2000). The selected fire probability model was as follows:

$$
\begin{aligned}
\text { Ign }_{c m p}= & b_{0}+b_{1} \text { DensRoad }_{c m p}+b_{2} \text { Ele }_{c m p} \\
& +b_{3} \text { BigRoad }_{c m p}+b_{4} \text { Urban }_{c m p} \\
& +b_{5} \text { AgricForest }_{c m p}+b_{6} \text { UrbanRural }_{c m p} \\
& +u_{c}+u_{m}+e_{c p}
\end{aligned}
$$

where $\operatorname{Ign}$ is the density of fire ignitions in plot $p$ of municipality $m$ and county $c$; DensPath is the density of paths and small roads (not in the national transport network), in kilometer per square kilometer; Ele is the $\log$ transformation of the elevation $(E l e=\ln$, elevation in meters); BigRoad is a dummy variable indicating the presence or absence of roads in the plot area (paved roads in the national transport network); Urban is a dummy variable indicating the dominance of urban land within the plot; and AgricForest and UrbanRural are dummy variables indicating the dominance of either agriculture-forest or urban-rural interface within the plot. Subscripts $c, m$, and $p$ refer to county, municipality, and plot, respectively. Finally, $u_{m}, u_{c}$, and $e_{c p}$ are the between-municipality, betweencounty, and between-plot random factors-independent and identically distributed-for ignitions within plot $p$, county $c$, and municipality $m$ and with $\mathrm{N}\left(0, \sigma^{2}{ }_{c}\right), \mathrm{N}\left(0, \sigma^{2}{ }_{m}\right)$, and $\mathrm{N}\left(0, \sigma_{c p}^{2}\right)$, respectively. These random factors repre- sent surrogates of alternative unobserved variables having effects at different spatial levels. The overall effect of these random effects is considered through an estimation of the variance, and its specific effect in every municipality and county division is calculated in the analysis.

Table 2 Estimates of the model parameters, statistical significance and standard errors

\begin{tabular}{lrrr}
\hline Eq. 1 (models for ignition density) & & & \\
\hline Parameter & Estimate & p-Value & $\begin{array}{l}\text { Standard } \\
\text { error }\end{array}$ \\
\hline Intercept & 0.225 & 0.031 & 0.1047 \\
DensRoad & 0.036 & 0.000 & 0.0053 \\
Ele & -0.138 & 0.019 & 0.0149 \\
BigRoad & 0.064 & 0.007 & 0.0150 \\
Urban & -0.438 & 0.001 & 0.1354 \\
AgricForest & 0.085 & 0.000 & 0.0143 \\
UrbanRural & 0.139 & 0.000 & 0.0371 \\
& & & \\
Variances of & & & \\
County factor $\left(u_{c}\right)$ & 0.166 & 0.000 & \\
Municipality factor $\left(u_{m}\right)\left(u_{m}\right)$ & 0.272 & 0.000 & \\
Plot factor $\left(e_{c p}\right)$ & 0.281 & 0.000 & \\
\hline
\end{tabular}

The mixed model (Eq. 1) includes parameters and estimates of between-county $\left(\sigma^{2}{ }_{c}\right)$ and between-plot $\left(\sigma^{2}{ }_{p}\right)$ variance 
a

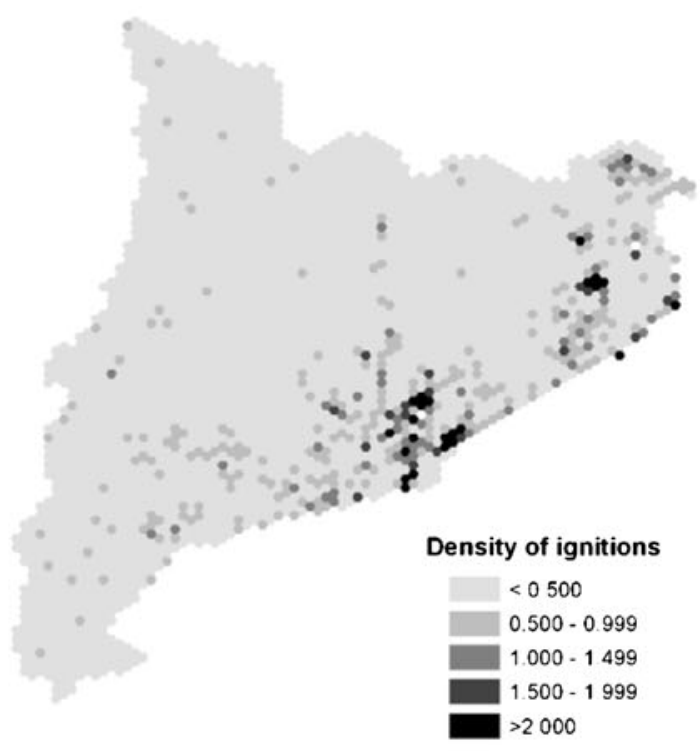

b

Predicted fixed

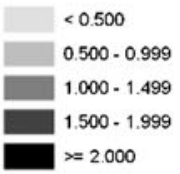

d

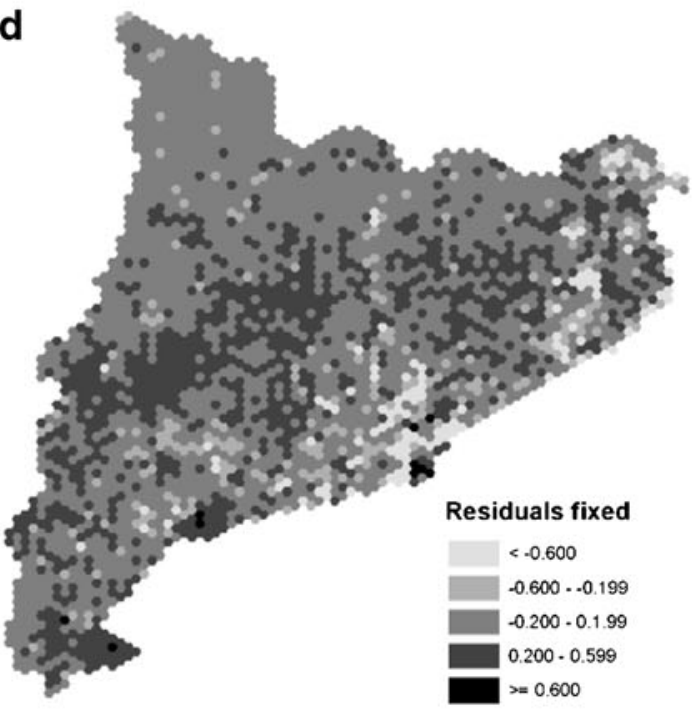

C

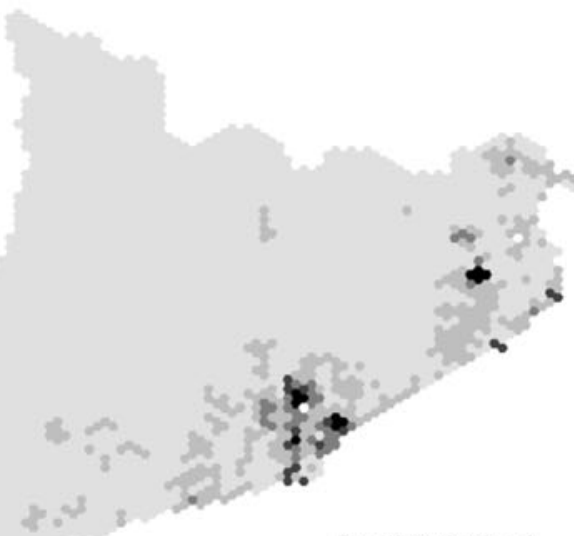

Predicted mixed

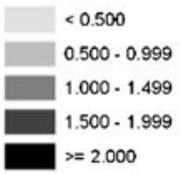

e

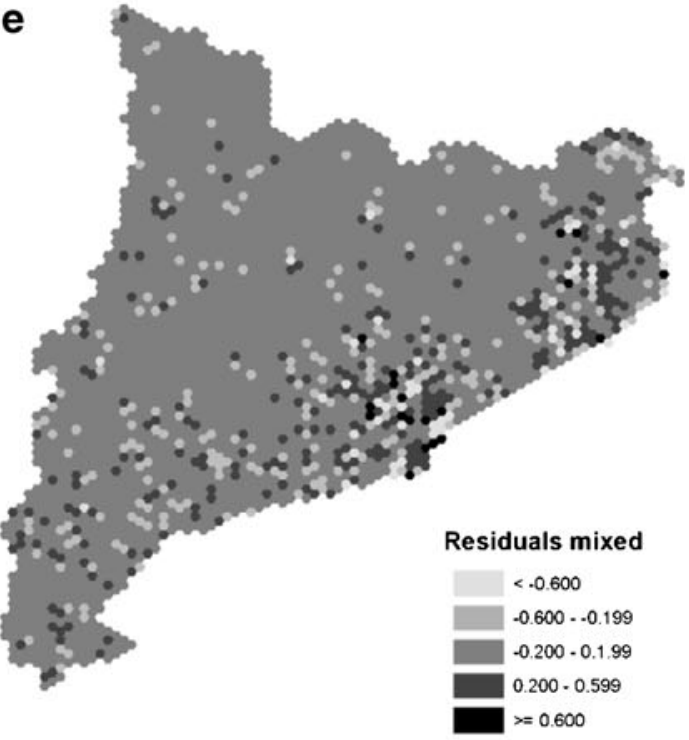


Fig. 4 Observed ignition densities (a), predicted ignition densities (b with the fixed part of the model and $\mathbf{c}$ with the mixed model), and residues of the ignition model ( $\mathbf{d}$ for the fixed part of the model and $\mathbf{e}$ for the mixed model)

The mixed model was evaluated by examining the magnitude and distribution of residuals and plotting the observed and predicted fire frequencies with the aim of detecting patterns flagging systematic discrepancies. In addition, the residuals of the fixed and random part of the model were geo-referenced and examined both visually and using Moran's index (Mitchell $2005)$ in order to detect possible geographical patterns.

\section{Results}

The coefficient of determination $\left(R^{2}\right)$ for the ignition model was 0.206 for the fixed part of the model (Fig. 3a). When between-county and between-municipality random factors were included, $R^{2}$ increased to 0.659 , showing a stronger correlation between observed and predicted values (Fig. 3b). According to the fixed part of the model (Table 2), the denser the road network gets, the higher number of ignitions can be expected in the plot. Presence of large roads further increased the number of predicted fire ignitions. As plot elevation increases, ignition density decreases. Plots falling within urban areas were less affected by fire ignitions, but if they fell into areas where urban and rural land-use patterns coexist or which are mosaics of agricultural and forest land, the number of ignitions per area unit increased.

Plotting observed versus predicted ignitions showed how the inclusion of the random effects associated with plot location within municipality or county boundaries improved the predictive capability of the models (Fig. 3b). Using only the fixed part of the model (Fig. 3a) not only led to larger error, but also the model showed a tendency to underestimate the density of ignitions in plots with a large number of observed ignition densities. However, this variation is partly explained by between-county (Fig. 3c) and betweenmunicipality (Fig. 3d) random factors and their inclusioncorrected part of this trend among the residuals.

Spatial analysis of the ignition densities showed a positive spatial autocorrelation between the observed values (Fig. 4a), with an estimated Moran's index of 0.44 and a $\mathrm{Z}$ score of 41.48. Visual comparison of the observed (Fig. 4a) and predicted ignition densities calculated with both the fixed part of the model (Fig. 4b) and the complete mixed model (Fig. 4c) revealed a clear improvement in the predictions when the mixed model was used. This improvement was also reflected in the magnitude and spatial location of residuals (Fig. 4d, e), which were smaller and randomly located when county and municipality factors were included in the mixed model. The estimated Moran's index for the residuals of the mixed model was 0.04 , with a $\mathrm{Z}$ score of 4.22 . This result indicates that including the random effects for each county $\left(\mu_{c}\right)$ and municipality $\left(\mu_{m}\right)$ (Fig. 5a, b) in the mixed model drastically reduced the spatial autocorrelation of the residuals.

Figure 5a, b gives estimated random effects for every county $\left(\mu_{c}\right)$ and municipality $\left(\mu_{m}\right)$. The figure shows that the model estimates the highest county effects near Barcelona City (solid black in Fig. 5a) and the coastal areas of Girona province (northeast Fig. 5a), whereas the lowest county effects are in western and central Catalonia. The southernmost corner of the region, hosting the River Ebro delta, also has a low county effect. The municipality effect estimated by the mixed model (Fig. 5b) does not follow spatial trends as clearly as the county effect, although the municipalities with highest incidence of ignitions are often located within high-risk counties.

\section{Discussion}

This study analyzed the spatial structure of long-term patterns of fire ignition in Catalonia during the period 1994-2007 in order to develop a model based on multiscale analysis to map the density of human-caused fire ignitions. The approach taken was to use a mixed model, which can separate the variability due to different grouping levels corresponding to the different administrative levels. Our initial hypothesis considered that the strong spatial autocorrelation in plot-level ignition patterns could not be adequately handled by conventional regression models. Díaz-Avalos et al. (2001) employed a similar ignition modeling approach working with a similar data structure, and the approach proved more adequate for hierarchically organized data. In this study, the use of a mixed model resulted in a spatial hierarchy based on plot level, municipality level, and county level.

The fixed part of this model targeted to plot level suggested that long-term prevalence of fire ignitions is mainly explained by variables related to topography, infrastructures, and land-use patterns. However, analysis of the variability caused by the additional spatial levels used as grouping factors confirmed that modeling at plot level is not enough to explain the variability in the ignition patterns, as there are strong regional differences acting at different scales. By considering the differences between municipalities and counties, the spatial variation was partially addressed and the potential effects of the variables considered at plot level were better addressed, thus avoiding possible confounding effects.

The variables selected as predictors in the fixed part of the model are consistent with the results of previous studies. Human accessibility, represented by density of 

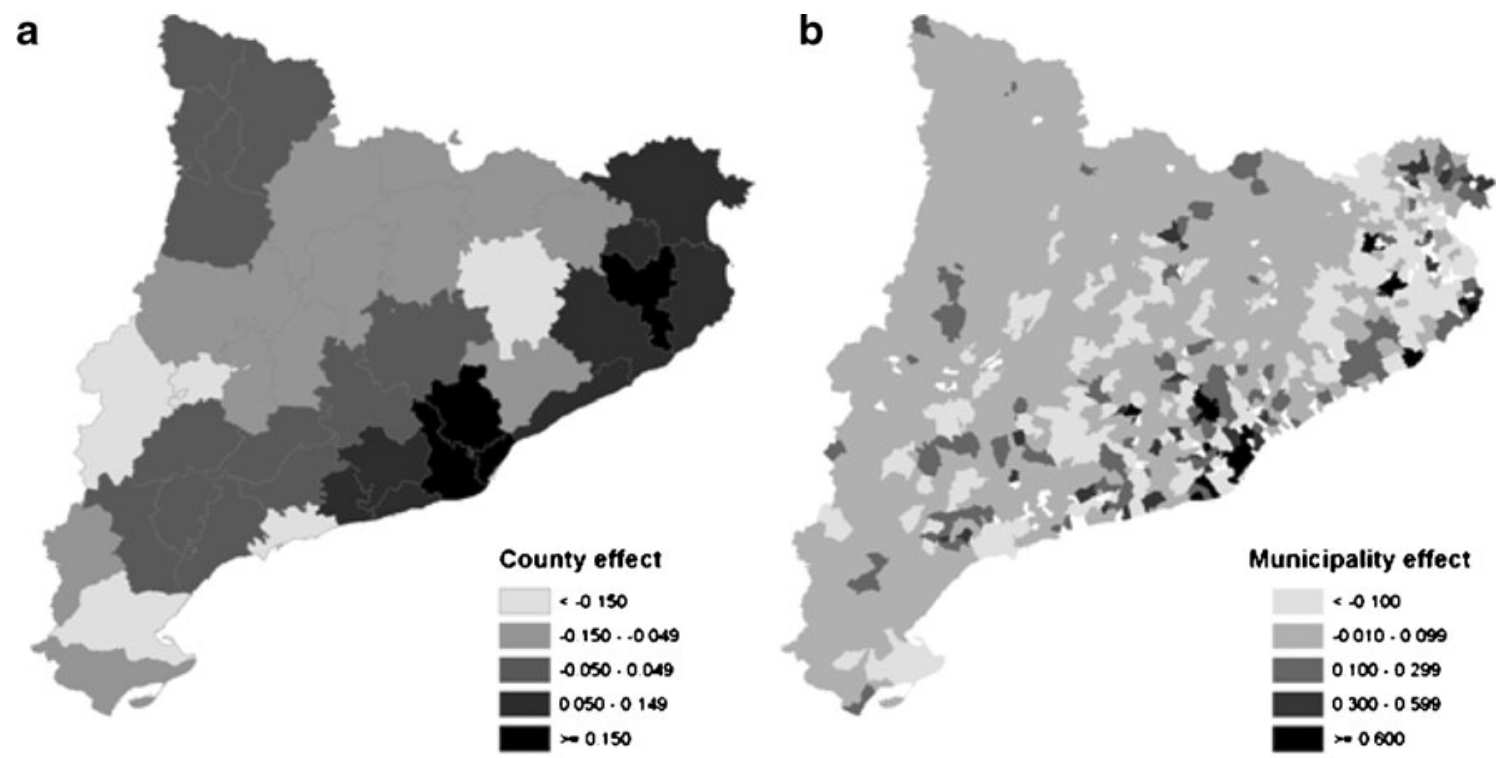

Fig. 5 Predicted random effects, for the counties (a) and for the municipalities (b)

pathways and presence of roads, has an important influence on the occurrence of ignitions (Chou et al. 1993; Cardille et al. 2001; Vasconcellos et al. 2001; Badia-Perpinya and PallaresBarbera 2006; Yang et al. 2007; Martinez et al. 2008). The effect of increasing elevation on expected ignition frequency has previously been reported by Vazquez and Moreno (1998) and Vasconcellos et al. (2001). One reason for this elevation effect may be the distribution of the population of Catalonia, which is concentrated in coastal areas, meaning population density decreases with increasing elevation (Badia-Perpinya and Pallares-Barbera, 2006). Another reason may be the correlation between elevation and climate (González et al. 2006), as lower elevations tend to be the more xeric places, offering dryer fuel. Regarding the effect of land-use allocation on fire frequency, the results were also as expected. Urban areas have fewer ignitions, which can be explained by the lower availability of forest and fuels to support forest fires. Whether plots interfacing agriculture and forest land-use or urban and rural land-use patterns were more prone to ignition. The positive correlation between agriculture-forest mosaics and occurrence of fires in Mediterranean areas has already been reported in several studies (Maselli et al. 2003; Amatulli et al. 2007; Martinez et al. 2008). There was an even stronger correlation between plots representing urban-rural interfaces and fire ignition density. This correlation can be explained by the presence of wildland-urban interface (Prestemon et al. 2002; BadiaPerpinya and Pallares-Barbera 2006; Syphard et al. 2007; Catry et al. 2009) or the presence of cities in the vicinity (Vega Garcia et al. 1995; Cardille et al. 2001).

The use of counties as a grouping variable is justified by their singular characteristics in terms of surface area, spatial distribution across the territory, and sociocultural homogeneity (DOGC 2003). The structural differences between counties in Catalonia and their influence on fire ignition regime were investigated previously by Badia-Perpinya and Pallares-Barbera (2006). In general, counties are large enough to contain a large number of study plots and represent enough within-county variability in terms of human-made infrastructures. In parallel, there are between-county differences in terms of land-use distribution and the relationship inhabitants hold with the surrounding environment that further supports the use of counties as a grouping variable. An additional advantage of incorporating administrative boundaries in the model is the possibility of exploiting statistical data on socioeconomic variables. Visual analysis concluded that highly populated counties, under the influence of large cities such as Girona and especially Barcelona, are the most affected by fires. The influence of Barcelona, which has hosts more than 1.5 million inhabitants within the city limits and a further 3 million in the surrounding metropolitan area, extends to the nearby counties where the large amount of periurban areas create a fire-vulnerable ignition-prone environment (Badia-Perpinya and Pallares-Barbera 2006). However, the presence of a metropolitan area in a county does not always imply an increment of ignitions: for example, some of the lowest frequencies of ignitions were found in counties surrounding the city of Lleida, where the low risk of fire ignition may be related to the highly intensive agriculture associated with large extensions of arable land in the nearby areas.

Municipalities were used in the study as another variable of spatial aggregation. Even though municipal-level analy- 
sis can provide important information on the effect of socioeconomic variables on incidence of ignitions, in the present study, its use was focused on capturing spatial variations in ignition density among plots and within counties. Spatial aggregation of fire ignitions can be expected to occur in the region depending on the specific cause of the fire, as is the case for arson (Prestemon and Butry 2005; Genton et al. 2006). The existence of "hotspots" (areas with an extremely high ignition density) due to the activity of an arsonist or other local socioeconomic factors can be considered as inducing positive bias in the our model's predictions of places where extremely high ignition frequencies are observed. The fact that hotspots are small enough to be unperceived at county level and large enough to affect various study plots justified the inclusion of an intermediate municipality effect in the model. The reductive spatial autocorrelation of the residuals of the mixed model may indicate that "hotspots" did occur across Catalonia. The municipality effect in the model partially solved the problem of spatially correlated residuals.

In this study, we grouped all human-caused ignitions to acquire a sufficient number of observations regardless of their specific causes. This allowed enough data for the application of the mixed modeling approach, and provided estimates of the variability of ignitions at different levels and taken as a whole, which was the initial objective of the study. If the data are treated separately according to the main causes of fire (Appendix 1), it can result in too few observations to identify spatial variation. However, there can be important differences in the factors explaining ignitions with different causes. For instance, human-caused ignitions can present wide casuistics, with a diverse range of socioeconomic factors influencing their aggregation in the space. In many cases, the factor or factors inducing the occurrence of a specific type of ignitions (in terms of their cause) either do not influence or negatively influence the occurrence of other types of ignitions. These aspects suggest that specific models combining all human-caused ignitions based on census data may lead to misinterpretations. For this reason, until studies are implemented for specific ignition causes, we suggest taking a visual approach to interpreting spatial variation in fire ignition density, comparing the spatial distribution of the random effects (Fig. 5) with the spatial variation of potential influencing factors (Appendix 2).

The results show that the county and municipal administrative units are relevant units for the analysis of long-term patterns of fire ignition density in Catalonia. However, this model is not aimed at predicting future occurrence of fire ignitions in Catalonia, but only at reflecting the relationship existing between static easily measurable variables and fire ignitions. In any case, the results of the present study should be combined with the results of other studies on the effect of meteorological variables on short-term ignition risk as a step toward optimizing preventive strategies.

Our findings highlight the importance of spatial variation in fire ignition density. Future studies are needed to improve our understanding of the fire ignition regime. An additional analysis of ignition causes and a spatially explicit approach addressing the "hotspot" areas would also provide valuable conclusions. Further research will be oriented toward detailed analysis of the socioeconomic factors that cause municipalityand county-level differences. The many potential factors and confounding factors will require confirmatory analysis. However, the methodological approach taken in this paper serves as a basis for these future studies.

Acknowledgments This work has received financial support from the Project Consolider Montes CSD2008-00040 granted by the Spanish Ministry of Education and Science (MEC). The authors thank the Department de Medi Ambient i Habitatge for providing ignitionrelated data and the Juan de la Cierva program from the Spanish Ministry of Science and Education for supporting the work of one of the authors. We are also grateful to Mr. Joan Pere Garrido for valuable guidance on handling the cartographic data.

\section{Appendix 1}

Table 3 Summary of fire ignitions by cause, recorded in Catalonia during the period 1994-2007

\begin{tabular}{lrcl}
\hline Cause & Number & Percentage & Group of cause \\
\hline Intentional & 2,530 & 24.5 & Intentional \\
Fire in dumping places & 108 & 1 & \\
Agricultural burning & 1,410 & 13.6 & \\
Bush burning & 11 & 0.1 & \\
Pasture burning & 206 & 2 & Negligence \\
Rubbish burning & 86 & 0.8 & \\
Bonfire & 255 & 2.5 & \\
Smokers & 727 & 7 & \\
Forest work & 362 & 3.5 & \\
Other negligence & 1,057 & 10.2 & \\
Military exercise & 16 & 0.2 & Accidents \\
Engines and machines & 327 & 3.2 & \\
Other accidents & 89 & 0.9 & \\
Human caused & 7,847 & 75.9 & \\
Revived wildfires & 98 & 0.9 & \\
Natural (lightning) & 1,128 & 10.9 & \\
Unknown origin & 1,256 & 12.2 & \\
Total & 10,330 & 100 & \\
\hline
\end{tabular}




\section{Appendix 2}
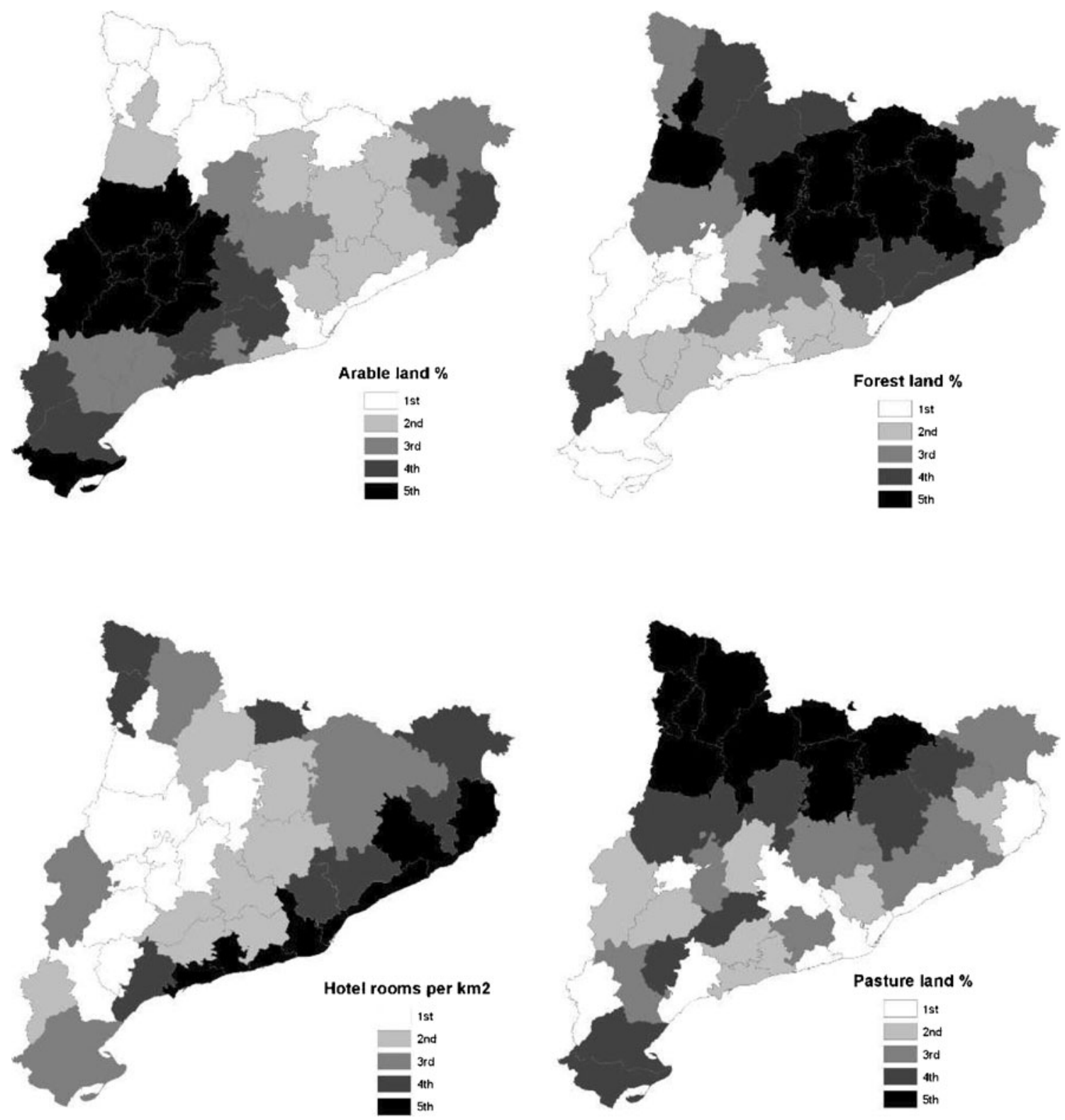

Fig. 6 Potential factors influencing the variation of fire density between counties (in quintiles)

\section{References}

Amatulli G, Perez-Cabello F, de la Riva J (2007) Mapping lightning/ human-caused wildfires occurrence under ignition point location uncertainty. Ecol Model 200:321-333

Badia A, Saur D, Cerdan R, Llurdes JC (2002) Causality and management of forest fires in Mediterranean environments: an example from Catalonia. Environ Hazards 4:23-32

Badia-Perpinyà A, Pallares-Barbera M (2006) Spatial distribution of ignitions in Mediterranean periurban and rural areas: the case of Catalonia. Int J Wildland Fire 15:187-196
BDN (2001) Mapa Forestal de España. MFE50 Escala 1:50000 Cataluña: Lérida, Gerona, Barcelona, Tarragona. Organismo Autónomo Parques Nacionales, Madrid

Cardille JA, Ventura SJ, Turner MG (2001) Environmental and social factors influencing wildfires in the Upper Midwest, United States. Ecol Appl 11:111-127

Catry FX, Rego FC, Bação FL, Moreira F (2009) Modelling and mapping wildfire ignition risk in Portugal. Int J Wildland Fire 18:921-931

Chou YH, Minnich RA, Chase RA (1993) Mapping probability of fire occurrence in San Jacinto Mountains, California, USA. Environ Manage 17:129-140 
de la Riva J, Pérez-Cabello F, Lana-Renault N, Koutsias N (2004) Mapping wildfire occurrence at regional scale. Remote Sen Environ 92:288-294

DGMN (2005) Las competencias de la CCAA en materia de prevención de incendios forestales. Internal report of the Department de Medi Ambient i Habitatge, Generalitat de Catalunya.

Díaz-Avalos C, Peterson DL, Alvarado E, Ferguson SA, Besag JE (2001) Space-time modeling of lightning-caused ignitions in the Blue Mountains. Oregon Can J For Res 31:1579-1593

DOGC (2003) LLEI 8/2003, de 5 de maig, de tercera modificació de la Llei 6/1987, del 4d'abril, de l'organització comarcal de Catalunya.

Genton MG, Butry DT, Gumpertz ML, Prestemon J (2006) Spatiotemporal analysis of wildland fire ignitions in the St Johns River Water Management District, Florida. Int J Wildland Fire 15:87-97

González JR, Pukkala T (2007) Characterization of wildfire events in Catalonia (north-east Spain). Eur J For Res 126:421-429

González JR, Palahí M, Trasobares A, Pukkala T (2006) A fire risk model for forest stands in Catalonia (north-east of Spain). Ann For Sci 63:169-176

Loboda TV, Csizar IA (2007) Assessing the risk of ignition in the Russian Far East within a modeling framework of fire threat. Ecol Appl 17:791-805

Martell DL, Otukol S, Stocks BJ (1987) A logistic model for predicting daily people-caused forest fire occurrence in Ontario. Can J For Res 17:394-402

Martinez J, Chuvieco E, Martin MP (2004) Estimating human risk factors in wildland fires in Spain using logistic regression. II. International Symposium on Fire Economics, Planning and Policy: A Global Vision, Córdoba, Univ. of Cordoba, CD-Rom: 15 pp.

Martínez J, Vega-Garcia C, Chuvieco E (2008) Human-caused wildfire risk rating for prevention planning in Spain. J Environ Manage 90:1241-1252

Maselli F, Romanelli S, Bottai L, Zipoli G (2003) Use of NOAAAVHRR NDVI images for the estimation of dynamic fire risk in Mediterranean areas. Remote Sen Environ 86:187-197

Mitchell A (2005) The ESRI guide to GIS analysis Volume 2: spatial measurements and statistics. ESRI Press, Redlands, pp 1-238

Pew KL, Larsen CPS (2001) GIS analysis of spatial and temporal patterns of human-caused wildfires in the temperate rain forest of Vancouver Island, Canada. For Ecol Manage 140:1-18

Pinheiro JC, Bates DM (2000) Mixed-effects models in S and S-PLUS, Statistics and Computing Series. Springer, New York, p 528
Piñol J, Terradas J, Lloret F (1998) Climate warming, wildfire hazard, and wildfire occurrence in coastal eastern Spain. Clim Change 38:345-357

Prestemon JP, Butry DB (2005) Time to burn: modeling wildland arson as an autoregressive crime function. Am J Agr Econ 87:756-770

Prestemon JP, Pye JM, Butry DT, Holmes TP, Mercer DE (2002) Understanding broad-scale wildfire risks in a human-dominated landscape. For Sci 48:685-693

Romero-Calcerrada R, Novillo CJ, Millington JDA, Gomez-Jimenez I (2008) GIS analysis of spatial patterns of human-caused wildfire ignition risk in the SW of Madrid (Central Spain). Landscape Ecol 23:341-354

Syphard AD, Radeloff VC, Keeley JE, Hawbaker TJ, Clayton MK, Stewart SI, Hammer RB (2007) Human influence on California fire regimes. Ecol Appl 17:1388-1402

Vasconcelos MJP, Silva S, Tome M, Alvin M, Pereira JMC (2001) Spatial prediction of FIRE ignition probabilities: comparing logistic regression and neural networks. Photogramm Eng Remote Sens 67:73-81

Vazquez A, Moreno JM (1995) Patterns of fire occurrence across a climatic gradient and its relationship to meteorological variables in Spain. In: Moreno JM, Oechel WC (eds) Global change and Mediterranean-type ecosystems. Springer Publishing, New York, pp 408-434

Vázquez A, Moreno JM (1998) Patterns of lightning-, and humancaused fires in peninsular Spain. Int J Wildland Fire 8:103-115

Vega GC, Woodard PM, Titus SJ, Adamowicz WL, Lee BS (1995) A logit model for predicting the daily occurrence of human-caused forest fires. Int J Wildland Fire 5:101-111

Vega GC, Woodard PM, Titus SJ, Adamowicz WL, Lee BS (1999) Dos modelos para la prediccion de incendios forestales en Whitecourt forest, Canada. Investigaciones agrarias: Sistemas y Recursos Forestales 8:5-24

Velez R (2002) Causes of fires in the Mediterranean Basin. EFI proceedings 45:35-42

Wotton BM, Martell DL, Logan KA (2003) Climate change and people-caused forest fire occurrence in Ontario. Clim Change 60:275-295

Yang J, He HS, Shifley SR, Gustafson EJ (2007) Spatial patterns of modern period human-caused fire occurrence in the Missouri Ozark Highlands. For Sci 53:1-15 